\title{
Active learning in optics and photonics
}

\author{
Joseph Niemela
}

Joseph J. Niemela, "Active learning in optics and photonics," Proc. SPIE 9946, Optics Education and Outreach IV, 99460L (27 September 2016); doi: 10.1117/12.2239579

SPIE Event: SPIE Optical Engineering + Applications, 2016, San Diego, California, United States 


\title{
Active Learning in Optics and Photonics
}

\author{
Joseph J. Niemela \\ The Abdus Salam International Centre for Theoretical Physics, Strada Costiera 11, Trieste, \\ Italy
}

\begin{abstract}
Active learning in optics and photonics (ALOP) is a program of the International Basic Sciences Program at UNESCO, in collaboration with the Abdus Salam International Centre for Theoretical Physics (ICTP) and supported by SPIE, which is designed to help teachers in the developing world attract and retain students in the physical sciences. Using optics and photonics, it naturally attracts the interest of students and can be implemented using relatively low cost technologies, so that it can be more easily reproduced locally. The active learning methodology is student-centered, meaning the teachers give up the role of lecturer in favor of guiding and facilitating a learning process in which students engage in hands-on activities and active peer-peer discussions, and is shown to effectively enhance basic conceptual understanding of physics.
\end{abstract}

Keywords: Hands-on, inquiry-based learning, student-centered learning

\section{INTRODUCTION}

The idea of creating an optics education program under the umbrella of UNESCO was first brought forward in 2003 in a meeting at the Abdus Salam International Centre for Theoretical Physics (ICTP) in Trieste where representatives from SPIE, UNESCO, ICTP and the Asian Physics Education Network (ASPEN) and others came together to share perspectives. The meeting was hosted by the late Gallieno Denardo, who had been given the task of developing an optics training program at ICTP some years earlier by Nobel laureate and ICTP Director Abdus Salam, even though it was relatively far from his own area of expertise (general relativity). This, in fact, was one of the hallmarks of the Centre in the early years, namely to encourage the scientific staff to devote a significant fraction of their time to developing and promoting research areas other than their own that might have more immediate impact on societies.

This text, taken from a memorial essay written in 2008 by then-ICTP Director K.R: Sreenivasan for the APS Forum on International Physics ${ }^{1}$ sums up Gallieno's approach:

"In particular, Gallieno saw optics, especially its experimental aspects, as an important ingredient needed for building the research infrastructure and teaching capacity of physicists in developing countries. Even though his own field of research was not optics, he saw its relevance for several areas of basic sciences, and, through the involvement of a number of interested people over the world, created a large optics community at ICTP. In particular, he used the ICTP College on Optics as a key mechanism for promoting research as well as training and educational activities in this broad field."

From the UNESCO side Minella Alarcon, with a background in experimental work on lasers and then the Physics and Math Programme Specialist at its headquarters in Paris, came with the idea of an educational program that mirrored the innovation in education that was fostered at the Ateneo de Manila University in Manila, Philippines where she had been a student. There has been a growing interest in inquiry-based techniques for teaching science, following the findings of Physics Education Research (PER) on campuses around the US and Europe, which addressed what many professors saw as a deficiency in undergraduate education. Indeed, while it is accepted and understood by most of us that solving problems at home with pencil on paper is indispensable to a proper training in the sciences, it is not clear at all that we are making wise use of the time in the classroom,

Further author information: Send correspondence to

Joseph Niemela

E-mail: niemela@ictp.it, Telephone: +390402240607

Optics Education and Outreach IV, edited by G. Groot Gregory, Proc. of SPIE Vol. 9946, 99460L (C) 2016 SPIE · CCC code: $0277-786 \mathrm{X} / 16 / \$ 18 \cdot$ doi: $10.1117 / 12.2239579$ 
where the homework is assigned. Certainly, this depends a lot on the individual instructor, but even with the best at the helm, is it really as effective as we would like to believe?

It seems that the answer is no; at least this is what Physics Education Research (PER) tells us, starting from the pioneering work of Lillian McDermott at the University of Washington, Dean Zollman (Kansas State), Fred Reif (Berkeley), David Sokoloff (University of Oregon), Rob Thornton (Tufts University), Priscilla Laws (Dickinson College), and others who have done the testing that shows the inadequacies of traditional teaching compared with inquiry-based or active learning techniques in the early years of study.

Minella, in an article in the Ateneo Physics News ${ }^{2}$ had this to say:

"The topics dealt with in PER look into how students learn and how to improve their learning of physics. In particular, PER has shown that teaching physics by lecturing is not effective at all and that students do not learn much from physics lectures. This conclusion was reached after several tests of conceptual evaluation were formulated by physicists and were administered to thousands of American students in introductory physics."

The move towards inquiry-based teaching strategies has been supported by several physics Nobel Laureates, including Georges Charpak, Carl Weimann, and Leon Lederman.

Why tinker with a system that has produced great scientists even with its inadequacies? There are several reasons, the obvious one being that there is always room for improvement and just because something works, e.g., the tungsten filament, the internal combustion engine, etc, it doesn't mean that there isn't a better technology around the corner, or a substantial improvement in existing technologies that can bring significant benefits to society. Another reason- that is really key to the idea of capacity building in developing countries, or the development of a knowledge-based society- is that we are not necessarily doing justice to the large numbers of students who should come away from their university years with some ability for critical thinking in science, but who otherwise have no intention to pursue it as a career. We scientists are naturally prone to tout the development of critical thinkers as a reason why any science should be funded (usually cited when the science in question has no immediate or obvious societal impact), but we shouldn't be satisfied with just a few critical thinkers, namely ourselves. If we can cultivate more of this variety of citizen, why not? In an increasingly technology-driven society, and with light-based technologies taking center stage, we need a public that can ask relevant questions and understand the importance of such technologies in improving their quality of life. Finally, there is another group of students- bright, creative and highly motivated, who are undecided about their future and who may wish to pursue further studies and a career in science but who are turned off by the dull routine of introductory courses. This is potential talent lost to the scientific community.

Bill Colglazier, former Science and Technology Adviser to the US Secretary of State, recently addressed this issue and the need for education reform ${ }^{3}$ :

"Building human capacity is the key element in creating an innovative society. We have turned off too many young people from science by teaching in boring ways emphasizing memorization of facts rather than teaching by inquiry and by having too many teachers in the early grades who are not adequately trained in the sciences and mathematics."

With this background, the idea of the meeting in Trieste was to explore how to take the lessons from PER to develop an adaptable course for teacher training based on active learning for the developing world, using optics and photonics as the topic, and with an application to the first years of an undergraduate course or the last years in high school. The goal was broad: help teachers teach more effectively while helping many of those same teachers improve their understanding of the material they are teaching, and generally help develop a culture that can support innovation through science and technology. There were a number of other people who were at that meeting and who helped shape the program in important ways: Eugene Arthurs, CEO of SPIE, brought a broad perspective on the role of optics in building innovative societies and the backing of a large international society with a keen interest in fostering optics capabilities in the developing world. Vengu Lakshminarayanan (Waterloo) and Zohra Ben Lakhdar, (an ICTP Associate from Tunisia and future UNESCO-L'Oreal prize winner for Africa) brought experience as successful academic researchers and educators from the developed and developing world respectively. Alex Mazzolini, Swinburne University, represented the Asian Physics Education Network (ASPEN) while Ivan Culaba and Joel Maquiling from Ateneo de Manila University, were already practiced in applications of low cost technologies in the classroom. 
David Sokoloff, a Millikan Prize winner and one of the recognized experts world-wide in active learning, as well as a future President of the American Association of Physics Teachers (AAPT), would meet Minella in Paris a few months later and together with the others named above formed the original team of facilitators. Gallieno Denardo had no intention of going on the road at that stage of his career, and so was more than happy to suggest to the present author that he join from ICTP's side in the first meeting of the facilitators at the Ateneo de Manila University, August 2004, some 10 months after the initial meeting in Trieste. This was the beginning of a long experiment in optics education under often difficult circumstances that is known as the Active Learning in Optics and Photonics program (ALOP).

\section{ACTIVE LEARNING}

How to make the biggest impact with limited resources and facilitator availability? ALOP from the beginning was aimed at teachers rather than pupils, with the idea that one motivated and educated teacher can reach many students. As mentioned above, the program took into account the fact that often those teachers attending the workshops had weak backgrounds themselves, so that a basic course was in some way also beneficial to them as students.

Apart from that, ALOP sought to give teachers modern pedagogical tools related to active learning, including the equipment and written materials and teacher's guides that went with it. This is important because active learning to be successful does not depend as much on the teacher's creativity in the delivery of facts as on their following a well-researched routine in which they take their students on a guided journey in class towards discovery. For teachers to abandon their usual "chalk and talk" routine requires that they acknowledge evidence obtained through PER that students in introductory courses often do not fundamentally change their misconceptions of how nature works even when their instructors provide what seem to them very logical explanations. This is often a difficult transition for teachers, who are self-selected somewhat by their incapacity to stop lecturing. As we might expect, the ability to step back is also governed to some extent by cultural factors.

So if professors don't profess, what do they do? In active learning they facilitate learning through a cycle that involves the students 1)making predictions based on their present knowledge, 2) having small group discussions about those predictions, 3) making observations to test the predictions and 4) comparing observed results with predictions and with others. It is those peer to peer discussions that make an active learning class seem like a soccer match compared to the usual classroom. This journey in class should be rather noisy, as the natural consequence of students thinking and communicating with others; In fact a quiet classroom is an indication that something is not working right. In a typical classroom setting, students talking to each other is generally not acceptable so this is a significant shift for both student and teacher. Indeed, this student-centered approach from the outside looks as though the teacher is not fully in control of their class. Of course this is not the case: the students are doing precisely what the teacher wants. They're learning. Peer-peer interactions are not only acceptable but are encouraged, as this is a natural consequence of students being actively engaged in the learning process. However, this might be a real concern in certain cultures and requires information to be shared also with the teachers' superiors.

Active learning, therefore, is not simply hands-on work- it also has a large amount of minds-on activity. In this scenario the teacher has a much different role: that of a facilitator to learning, rather than that of lecturer and authority. Indeed, the observations made by the students become the authority.

Since students learn concepts through their own observations, their perception of the physical laws at work are directly challenged by those observations, whereas in a passive lecturing setting this confrontation doesn't necessarily happen. It is useful to note that there is an important difference between the observation cycle mentioned above and that of a typical laboratory class. In the latter, the measurements are used to "confirm" the theory learned in lecture, while in the active learning situation the learning stems from the facilitated observations themselves, in a manner that is reminiscent of how science actually works. In fact, one needs only remember the motto of Nobel Laureate Heike Kamerlingh Onnes, the first person to liquefy helium and subsequently discover superconductivity, which was prominently displayed in his laboratory: "Knowledge through Measurement". 


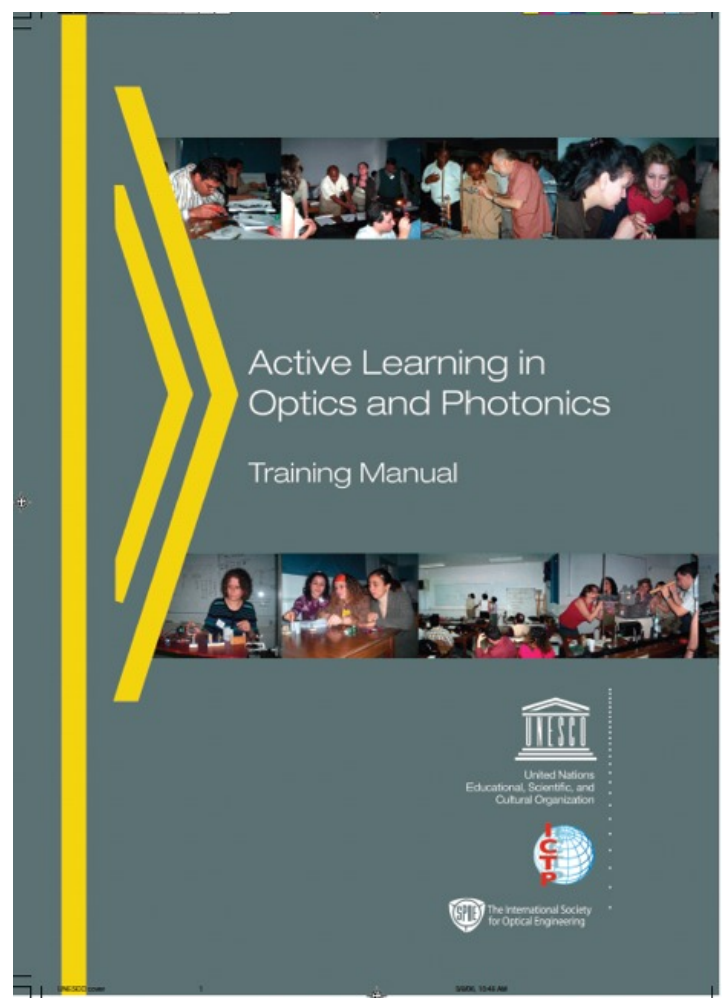

Figure 1. Key to the workshops are the student manuals and teacher's guide provided to all participants. The manual is available in English, French, Spanish, and Arabic.

\section{ALOP WORKSHOPS}

The ALOP teacher-training workshops rely on the use of low cost equipment and resources appropriate for developing countries. While the program had its patronage and some basic funding from UNESCO and ICTP, it is able to run well because of the support it has received from other organizations. Most notably, SPIE has been the principal supporter of the program over its entire 12 year history. Additional support has been provided by OSA, EPS, Essilor, ICO, NAS, and other organizations.

A 5-day workshop, together with an associated manual and teacher's guide (see Fig.1), was developed using the following modules: Introduction to Geometrical Optics; Lenses and Optics of the Eye; Interference and Diffraction; Atmospheric Optics; Optical Data Transmission, and Wavelength Division Multiplexing. Ideally there are only 30-40 participants so that ten setups can accommodate around 3-4 people each. Because the program lives under the umbrella of PER it is important to assess the learning that takes place, and for that reason a special test, derived from PER, is given at the beginning and end of the workshop, focused on measuring conceptual understanding.

Light education loves the dark, and indeed, one of the most difficult things to locate in a particular venue is a room that can be totally darkened. A solution we found that works reasonably well is to buy some aluminum foil and tape it to the windows. It may be thin (typically of order 20 microns) but the penetration depth of visible light is much smaller so it works fine and is not as expensive as installing curtains.

Because some of the activities- especially optics of the eye- require that lenses be placed at known and fixed distances from each other and from the light source and screen, we originally specified that optical rails should be made available, being something that is typically in abundance at a university in Europe or North America. Well, that is not really true around the world and even if the rails are present you also need sufficient numbers of lens holders and mounts. Solution: a meter stick and a bit of putty works wonderfully (see Fig. 3) and is certainly easier to move aside when not needed! As well, we don't need precision optics for demonstrating basic 


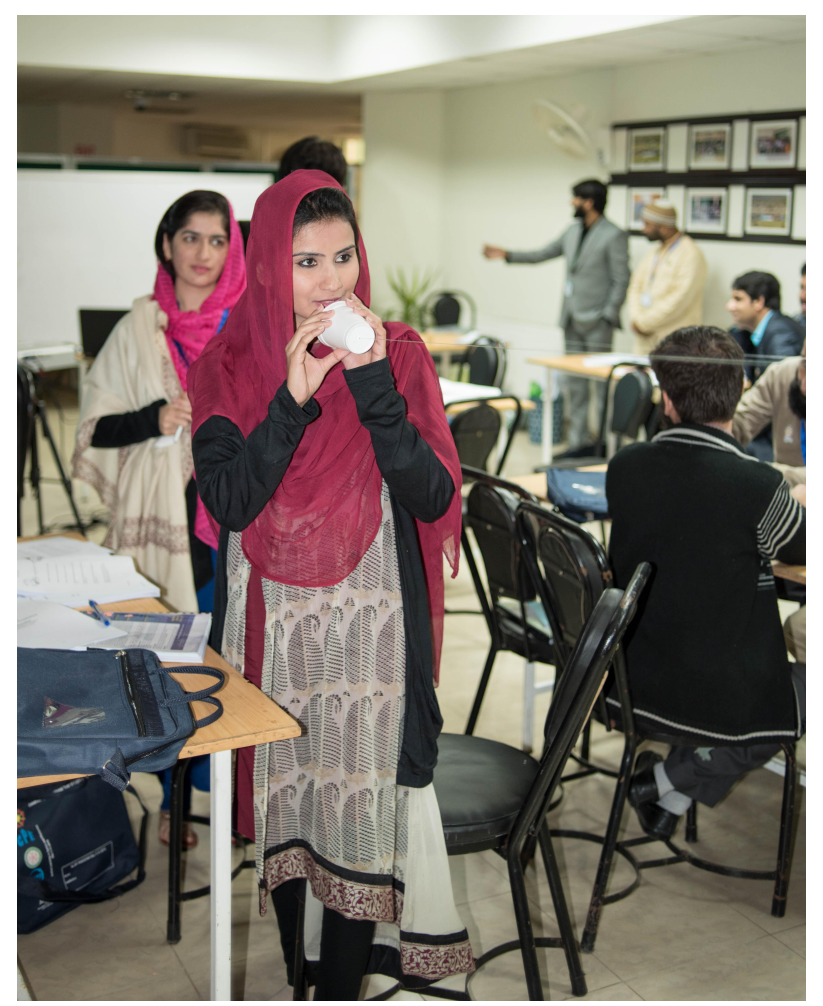

Figure 2. Participants in an ALOP at the National Center for Physics in Islamabad exploring wave transmission basics with a string phone. Photo credit: J. Niemela

principles and the price difference between "good" lenses and "good enough" ones can be significant, especially if your department doesn't have that much money to begin with.

One of the most important requirements for a successful workshop is to have a resource room available nearby the classroom so that facilitators can prepare their modules, integrating any equipment they may have brought with materials provided by the local hosts (see Fig.4).

Before a workshop begins it is useful to break into small groups to discuss the nature of problems encountered in teaching. It is probably no surprise that the everyday concerns of teachers in North America and Europe appear to be the same as those in sub-Saharan Africa. Other problems are common in theme but have regiondependent scales, such as "lack of adequate resources," a commonly heard comment anywhere in the world. It is, of course, a much larger problem in the least developed countries, and this is why the emphasis on a curriculum that combines active learning with low cost technologies is needed.

Another lament often heard concerns large classes- meaning a couple hundred or more students- and here it might seem that active learning would be difficult. However, it can still be introduced into the classroom to some extent through so-called interactive lecture demonstrations in which the hands-on component is handled solely by the instructor who uses suitable techniques for projecting the demonstration, while the minds-on part remains with the students. ${ }^{4}$ This is another example of why active learning can't simply be described as "hands-on."

Violence in the schools is rarely brought up as a general everyday concern in the context of these workshops; those who teach in the middle schools all suffer, of course, from the kind of war zones created by gathering together large numbers of adolescent children in one place. And for all educators, the remote possibility that a disturbed individual will bring violence to a school is enough to negatively alter at least in some way the required nurturing environment. It is important, however, to point out that schools in certain areas around the world suffer by being specifically targeted for violence by external,armed groups opposed to education, especially for girls. In a sense, it underscores the real power of education and the threat that it poses for such groups. Against this 


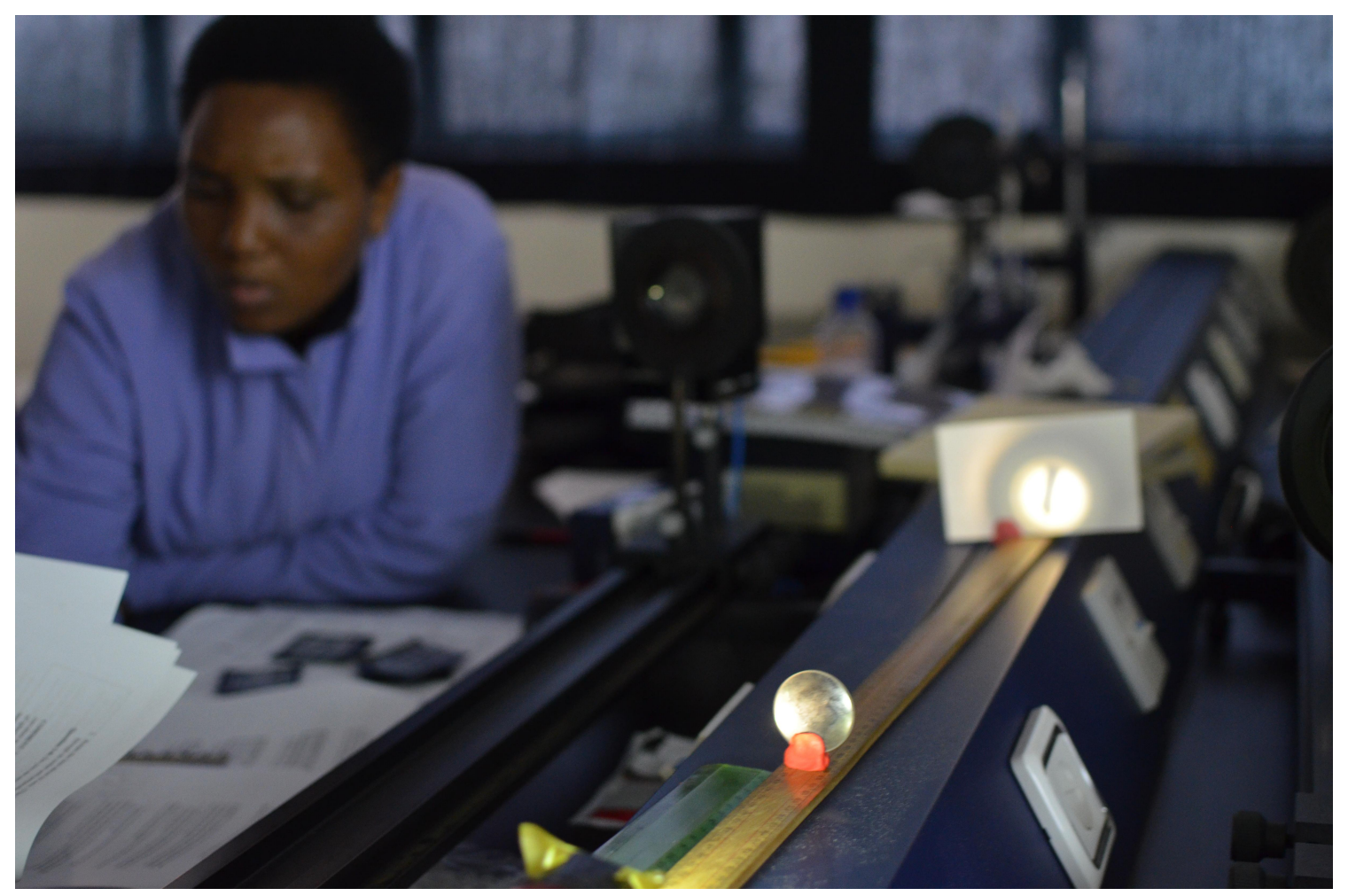

Figure 3. Unlike in physics departments in North America or Europe it is not always possible to locate 10 optical rails in developing countries for placing lenses at prescribed distances from a light source and screen. We have found that meter sticks and putty work fine for the modules and seem to be universally available. Photo credit: J. Niemela

backdrop have emerged people with exemplary courage, such as the young student Malala Yousafzai who refused to accept the notion that girls should not also participate in the educational process. Malala did not have the stature of Mohammad Jinnah, the statesman who summoned up enormous courage in the founding of her country Pakistan- she just wanted to go to school. Indeed, John F. Kennedy remarked ${ }^{5}$ "To be courageous...requires no exceptional qualification...It is an opportunity that sooner or later is presented to us all."

One of the measures of success of the ALOP program is the desire and drive of certain motivated former participants to organize locally ALOP-style workshops aimed at helping local teachers. These are sometimes abbreviated versions of the original ALOP; the point is that they are sharing their know-how. The ALOP team is always ready to help with mentoring, equipment, manuals, and when feasible the presence of one of the facilitating team to guide the process for the first time at least. Such participants have been instrumental in helping to translate the teaching materials in French, Arabic and Spanish. North Africa (Tunisia and Morocco) have held many additional workshops after the original ALOPs in their countries, and this is also true in Nepal. In South America, Angela Guzman (Florida Atlantic) has been particularly active in organizing ALOP activities, delivered in Spanish, throughout the region, finding local resources to help fund them and enlisting the help of a number of skilled facilitators coming from previous ALOP activities on the continent and from the follow-up courses as well.

In all, 27 ALOPs under the umbrella of UNESCO have taken place in 26 developing countries and one more is planned for late 2016 in Namibia. Taken together, ALOP has trained over 1000 teachers in nearly 60 countries. These workshops have been hosted in Africa, Asia, Central America and South America. These workshops with the core group have been augmented by many others described above so that the reach has been much wider.

It bears mentioning that during the International Year of Light and Light-based Technologies (IYL 2015), ALOP became a centerpiece in its light education platform, with 6 workshops carried out (in Indonesia, Mauritius, South Africa, Mexico, Bolivia, and Pakistan). It is currently one of the principal legacy actions for IYL 2015. 


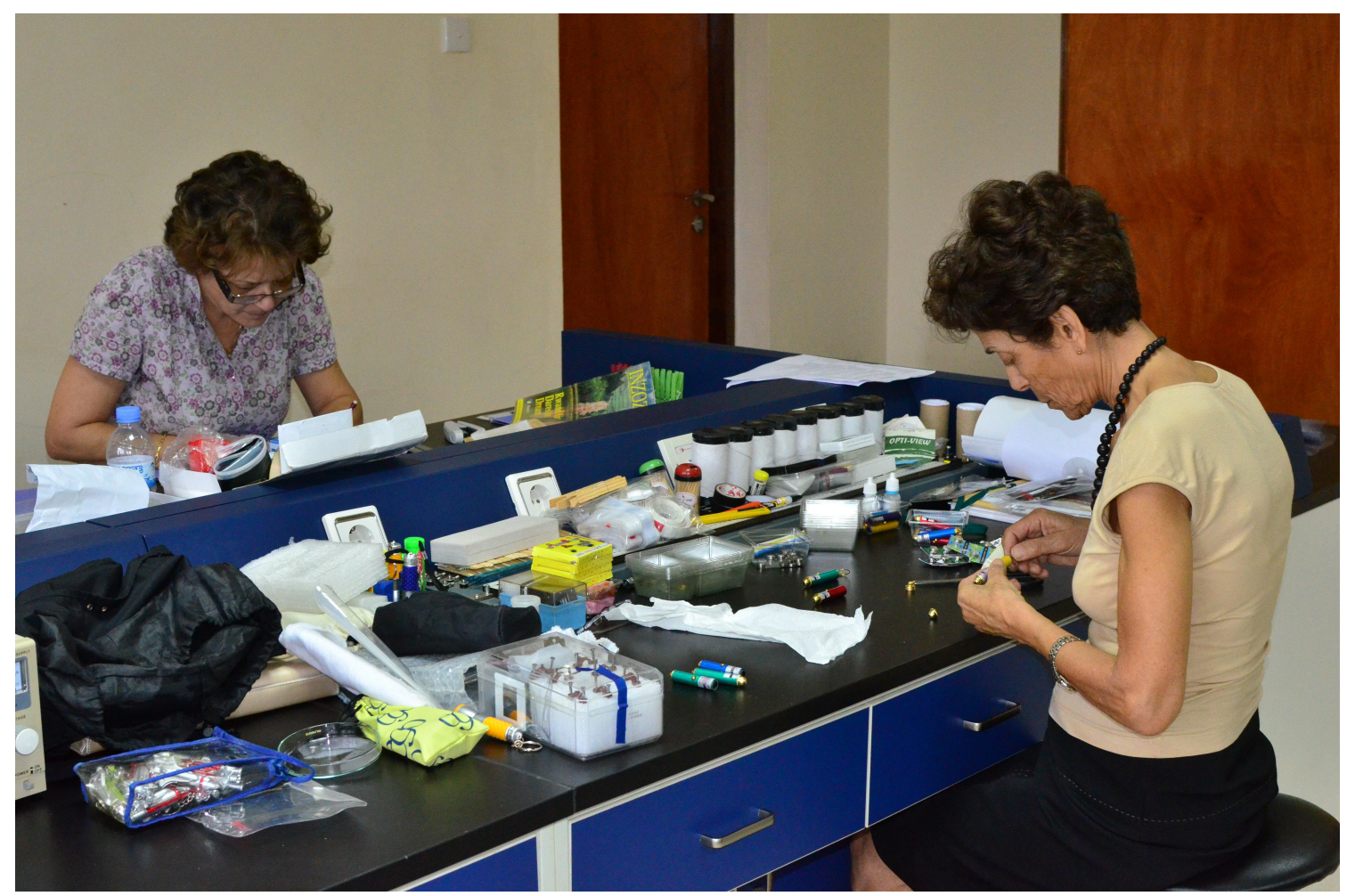

Figure 4. Having a room available for preparation of module equipment that is also close to the session room is an important requirement for ALOP workshops. Pictured here are Profs. Zohra Ben Lakhdar and Souad Lahmar from Tunisia preparing their respective modules in Rwanda. Photo credit: J. Niemela

\section{WHERE TO NEXT?}

With its reach to teachers around the world and the follow-up activities that have ensued, ALOP has already had much success. However, the ultimate goal is not to simply inform teachers, but to effect change. To have active learning accepted in schools anywhere in the world requires getting the approval of those who set the curriculum. Ironically, it may be easier in the developing world than in parts of North America, where teaching is often aimed at getting students past comprehensive state or national examinations. The problem, in some sense, mirrors the modern problem of drinking and driving. In Italy the latter concern was expressed in this way by one of my neighbors: "What problem of drinking and driving? The problem is not drinking...it is driving!" Analogously, the problem of having students preparing for exams during their schooling is, in fact, the exams themselves. If you only test for memorization of facts then you end up with a system that is not adequately preparing students to populate an innovative society, as noted in the above remarks by Bill Colglazier.

To get ALOP into the classroom requires both bottom-up (ALOP participants) and top-down (Ministry of Education) involvement and for this reason we try to engage with the Minister, or someone from the Ministry, in our activities. The idea of pilot projects of short duration seems to have some appeal, as it does not require a political pay-out at the top, nor does it present an overwhelming amount of change for the teacher.

As a precursor to taking ALOP into the classroom, we recently experimented with trying it out with real students rather than our knowledgeable instructors who took on that role. A few volunteer-fueled projects were started in Pakistan, following the ALOP workshop that took place there in December 2015. Specifically, these activities involved a number of features of active learning in optics and photonics, while stopping short of actually reproducing the week-long activity, which would have required more negotiations. These activities were aimed at all-girl high schools and later undergraduate women at Quaid-i-Azam University in Islamabad. Future activities are being planned outside the Islamabad area, in poorer public schools near Abbottabad in the 


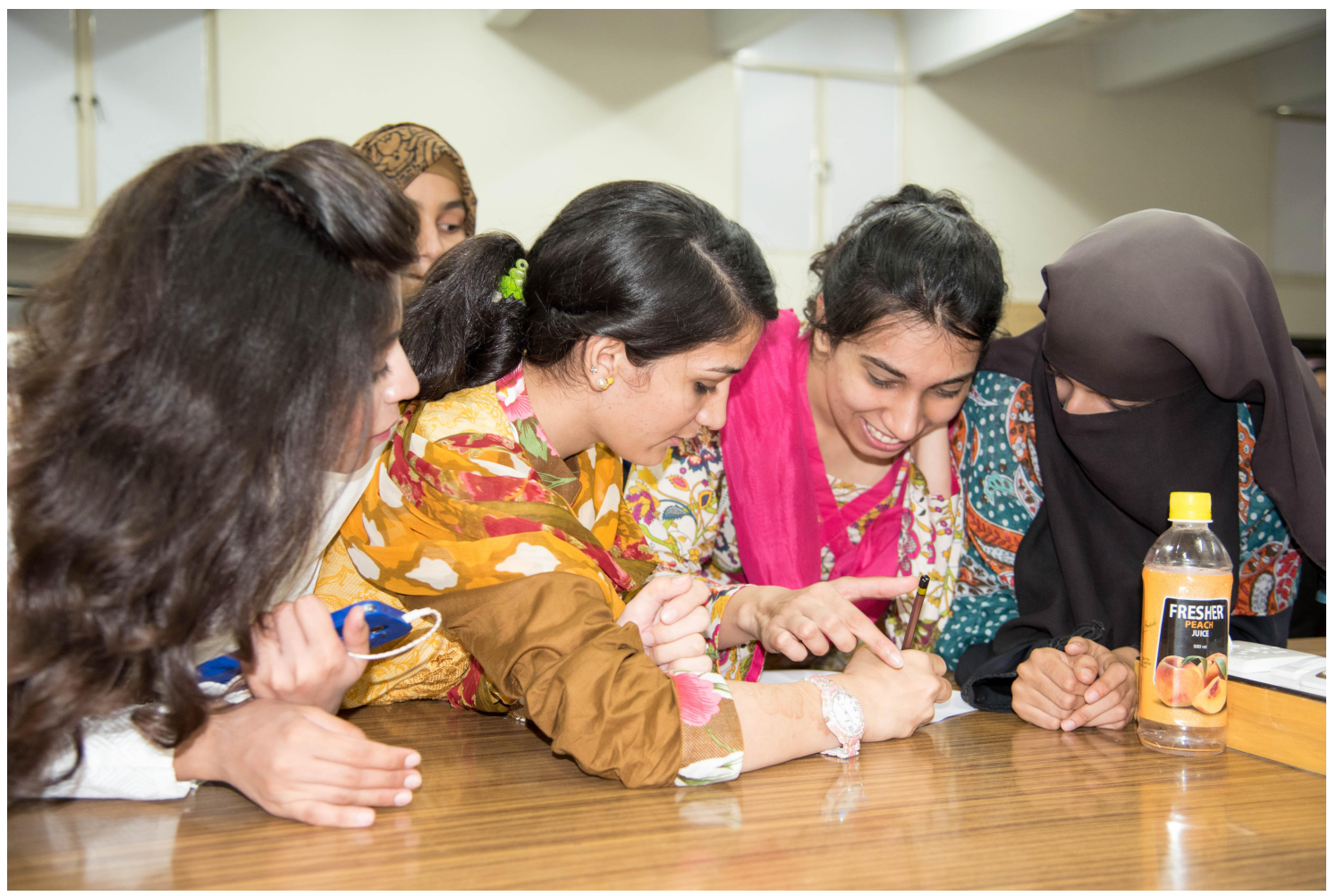

Figure 5. Part of the active learning environment is the free discussion that precedes and follows observations among members of individual groups. In this case, the discussion is among undergraduate students at Quaid-i-Azam university in Islamabad, participating in a special one-day active learning workshop. Photo Credit: J. Niemela

Khyber Pakhtunkhwa region, some of which do not have electricity and where students will be seeing laboratory equipment probably for the first time. Taking care of this on the ground are Imrana Ashraf Zahid (Quaid-iAzam University), an ICTP Senior Associate and ICO-ICTP prize winner, Jehan Ahkbar (Hazara University), ICTP junior Associate and also a ICO-ICTP prize winner, and Raheel Ali (physics lecturer at Quaid-i-Azam University). It is important to note that we are targeting only public schools, where the greatest need is. For these preliminary activities we have been adapting optics kits developed by Photonics Explorer, ${ }^{6}$ and donated by the ICTP, so that the cost of running these workshops is near zero. More recently, some kits dedicated to IYL 2015 and aimed at middle school age children were donated by the American Physical Society (APS), and these are destined for the northern Gilgit-Baltistan region, by the same local team.

Finally, it is important to continuously bring in new talent to the ALOP team, both to reinvigorate it with new ideas and to have an ever-expanded pool of facilitators that can respond to the demand for workshops. Taking away the factor of limited funding, there is a huge demand that could not realistically be met by the present team. In terms of new modules, we should note that an important part of ALOP is to bring students a closer exposure to the connection between science and society through optics and photonics applications. In some sense this is bringing a small part of what science centers do into the classroom. Gaining an appreciation for the ways in which optics and photonics impacts our lives always produces a level of fascination in students, and as there is no shortage of new and exciting applications, the main difficulty is in making sure that new modules correctly integrate active learning. By enlisting early career scientists in this endeavor, we can also help them get involved in international development activities early on. Since they would not be able to take much time away from their duties, we really do need an expanded team so that each facilitator can limit their participation (which requires traveling to remote areas where teaching at a distance doesn't always work to cover their absence from their own classrooms). Nobody can get up to speed immediately, so there is no substitute for experienced facilitators on each team to provide the wisdom and organizational ability gained from many 


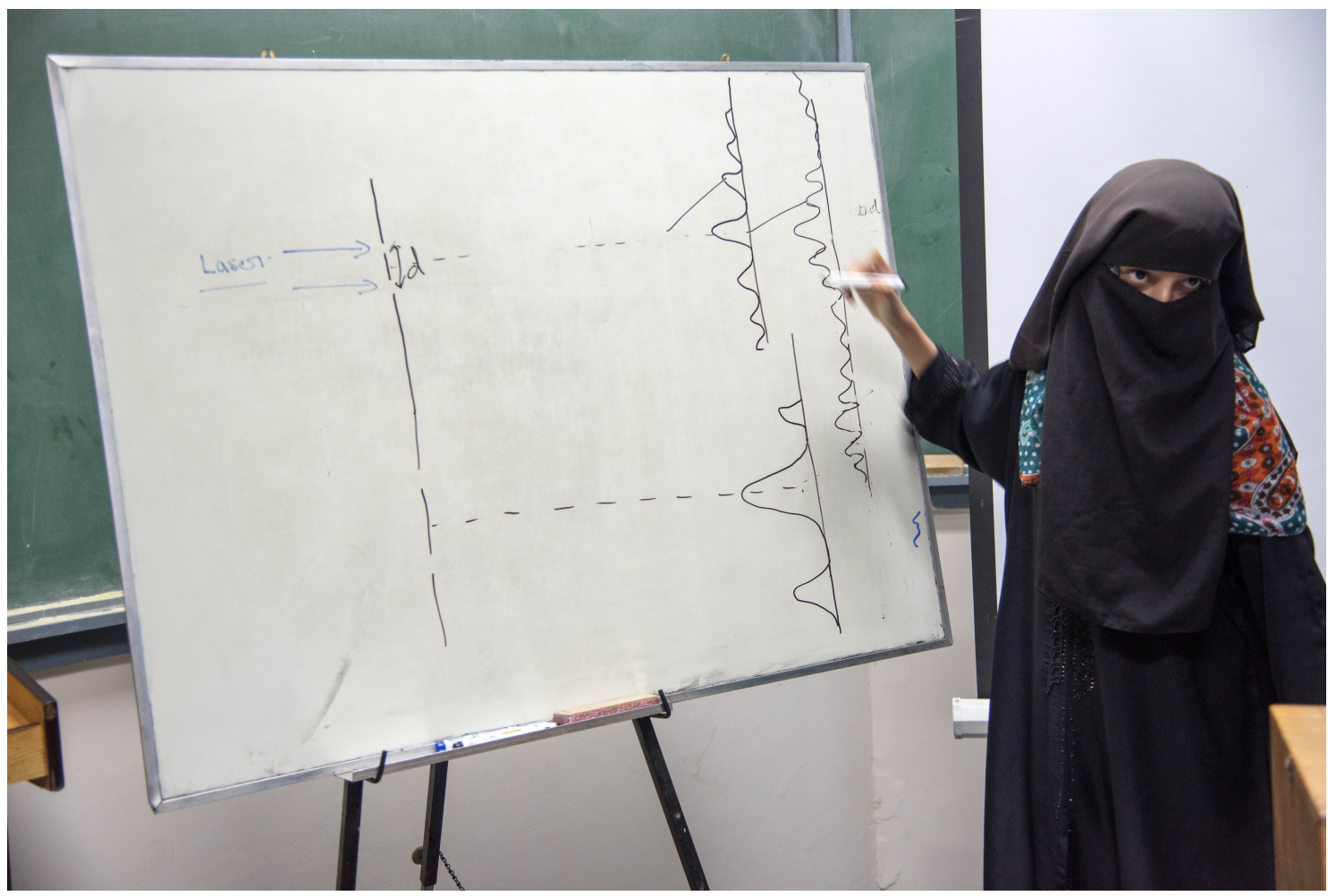

Figure 6. After individual groups have completed their own discussions, one person from each group acts as a spokesperson and communicates their findings to the entire class. Photo credit: J. Niemela

experiments in the the field, where, as a general rule, if things can break, they will! For the younger facilitators especially, accomplishing your goals under difficult conditions, and in spite of unexpected complications, is, in fact, a valuable experience that is well-recognized by employers. For any one of us, seeing the excitement of teachers and students as they explore the active learning environment is an experience that is unforgettable!

\subsection{Acknowledgments}

The author wishes to thank not only the facilitators of the ALOP program for the time and effort they have volunteered over the years, but also to the many wonderful people within SPIE who have made it possible for the program to succeed.

\section{REFERENCES}

[1] http://www.aps.org/units/fip/newsletters/200805/denardo.cfm

[2] https://ateneophysicsnews.wordpress.com/tag/dr-minella-alarcon/

[3] "Science and Diplomacy in the 21st Century", 46th Session of the Erice International Seminars "Role of Science in the Third Millennium" August 20, 2013, Erice, Sicily.

[4] David R. Sokoloff and Ronald K. Thornton, "Using Interactive Lecture Demonstrations to Create an Active Learning Environment," The Physics Teacher 35: 6, 340 (1997).

[5] John F. Kennedy "Profiles in Courage" HarperCollins (New York) 2006.

[6] www.eyest.eu/STEM-Programs/Photonics-Explorer 